\title{
CHROMOSOMAL Q-HETEROCHROMATIN POLYMORPHISMS IN 3 ETHNIC GROUPS (KAZAKHS, RUSSIANS AND UYGHURS) OF KAZAKHSTAN
}

\author{
IBRAIMOV A.I. ${ }^{1,2^{*}}$, AKANOV A.A. ${ }^{1}$, MEYMANALIEV T.S. ${ }^{1}$, KARAKUSHIKOVA A.S. ${ }^{1}$, KUDRINA N.0. ${ }^{1}$, \\ SHARIPOV K.0. ${ }^{1}$ AND SMAILOVA R.D. ${ }^{1}$
}

${ }^{1}$ Kazakh National Medical University after name S.D. Asfendyarov, Tole bi str., 88, Almaty, KZ-050012, Kazakhstan.

2Laboratory of Human Genetics, National Center of Cardiology and Internal Medicine, Togolok Moldo str., 3, Bishkek, KG-720 040, Kyrgyzstan.

*Corresponding Author: Email- ibraimov_abyt@mail.ru

Received: December 14, 2012; Accepted: January 7, 2013

\begin{abstract}
A comparative study of polymorphic variants of chromosomal Q-heterochromatin regions (Q-HRs) was performed in three ethnic groups (Kazakhs, Russians, and Uyghurs) of Kazakhstan. The number of chromosomal Q-HRs in the genome of studied individuals ranged from 0 to 7, with the mean 3.51, 3.51 and 4.15 in Kazakhs, Russians, and Uyghurs, respectively. The studied Kazakhs and Russians showed statistically significant homogeneity in the distribution of the number and mean number of Q-HRs, while the highest amount of chromosomal QHRs revealed in the Uyghur group. Differences and homogeneity between these three groups in the amount of Q-HRs in their genome are discussed as evidence in favor of the hypothesis of the possible selective value of chromosomal Q-heterochromatin material in human adaptation to various climate-geographic conditions.
\end{abstract}

Keywords- chromosomal Q-heterochromatin, Q-heterochromatin polymorphism, human adaptation, human migrations

Citation: Ibraimov A.I., et al. (2013) Chromosomal Q-Heterochromatin Polymorphisms in 3 Ethnic Groups (Kazakhs, Russians and Uyghurs) of Kazakhstan. International Journal of Genetics, ISSN: 0975-2862 \& E-ISSN: 0975-9158, Volume 5, Issue 1, pp.-121-124.

Copyright: Copyright(02013 Ibraimov A.I., et al. This is an open-access article distributed under the terms of the Creative Commons Attribution License, which permits unrestricted use, distribution and reproduction in any medium, provided the original author and source are credited.

\section{Introduction}

The existence of variability in the number, frequency, size, and intensity of fluorescence of chromosomal Q-heterochromatin regions (Q-HRs) in twelve polymorphic loci of seven autosomes and on the distal portion of the long arm of chromosome $Y$ is a wellestablished fact. The existence of considerable interpopulation differences in certain quantitative characteristics of this variability is supported by reliable data [1-15].

However, there is no agreement as to the nature of broad quantitative variability of chromosomal Q-HRs, although arguments are based on the 'selectionist' hypothesis. The aim of this report was to describe the chromosomal Q-HRs variability in the genome of the three most numerous ethnic groups permanently residing in southern Kazakhstan and compare them with the previously studied populations.

\section{Materials and Methods}

\section{Sample Characteristics}

The Kazakhs, during their ethno-genetic development at the territory of modern Kazakhstan, formed three large tribal communities, so -called Joozes (Senior, Middle, and Junior). Senior Joozes lives in the southern part of modern Kazakhstan, including Almaty, the former capital of this Republic.

The first Russian migrants from various regions of the Russian Empire appeared on the territory of contemporary Kazakhstan only at the end of the XIX century. The contemporary Russian population of Kazakhstan is no less heterogeneous, as unlike the native residents of this Republic. In addition, after the collapse of the Soviet Union there was a mass emigration from Kazakhstan to Russian Federation. Therefore, complete genetic continuity between the studied Russians of Kazakhstan and the first migrants of from Russia is not possible.

There are over 10 million Uyghurs living around the world. The major share of them still live in the Xinjiang Uyghur Autonomous Region of the People's Republic of China and around 400 thousand Uyghurs live around Central Asia with half of this figure residing in the Republic of Kazakhstan. This ethnic group is the third largest one in the Almaty region. The appearance of the Uighur ethnic group was first mentioned in Kazakhstan at the end of the 19th century. By 1897, there were already roughly 56,000 Uyghurs in what is today Kazakhstan, according to the Russian Empire Census. During the 1950s in China, ethnic tensions and repression of minority separatist movements led to a mass exodus from Xinjiang to the Kazakh SSR. They came to various areas of Kazakhstan, especially southern Kazakhstan, in the late 19th and early 20th century. Most of the more than 200,000 Uyghurs in Kazakhstan trace their roots to the migrations during the 1950s and 1960s.

We studied 131 Kazakh, 33 Russian, and 40 Uyghur students from Kazakh National Medical University named after S.D. Asfendyarov in Almaty. In the studied samples young men and women whose parents were from the same ethnic group are included. Henceforth the first group is referred as Kazakhs, the second Russians, and the 
third as Uyghurs. The age of students ranged from 18 to 25 years.

\section{Cytogenetic Methods}

Chromosomal preparations were made using short-term cultures of peripheral blood lymphocytes. The cultures were processed according to slightly modified [21] conventional methods [16]. The dye used was quinacrine mustard ('Sigma-Aldrich', USA). The calculation and registration of chromosomal Q-HRs variants performed using the criteria and methods described in detail elsewhere $[4,6]$.

\section{Quantitative Characteristics of Q-HRs Variability and Methods Used for Comparisons}

The following quantitative characteristics of chromosomal Q-HRs variability were used:

1. The distribution of individuals according to the number of QHRs in their karyotype in population (distribution of the number of Q-HRs);

2. The derivative of this distribution, an important population characteristic, is the mean number of Q-HRs per individual;

3. The Q-HRs frequencies in each of the twelve polymorphic loci of seven autosomes $(3,4,13-15,21$ and 22).

The mean numbers of $\mathrm{Q}-\mathrm{HRs}$ per individual were compared using Student's t-test.

\section{Results and Discussion \\ Results}

The three samples were compared as to the distribution of the number and mean number of chromosomal Q-HRs per individual in population [Table-1].

Table 1- Distribution of numbers and mean number of chromosomal Q-HRs in Kazakh, Russian and Uyghur samples in Almaty

\begin{tabular}{|c|c|c|c|}
\hline \multicolumn{4}{|c|}{$\begin{array}{ll}\text { Populations } \\
\end{array}$} \\
\hline Number of Q-HRs & $\begin{array}{l}\text { Kazakhs (Almaty) } \\
\quad(n=131)\end{array}$ & $\begin{array}{c}\text { Russians (Almaty) } \\
\quad(n=33)\end{array}$ & $\begin{array}{l}\text { Uyghurs (Almaty) } \\
\qquad(n=40)\end{array}$ \\
\hline 1 & $14(10.7)$ & $2(6.0)$ & $1(2.5)$ \\
\hline 2 & $18(13.7)$ & $6(18.2)$ & $5(12.5)$ \\
\hline 3 & $32(24.4)$ & $11(33.3)$ & $7(17.5)$ \\
\hline 4 & $33(25.2)$ & $5(15.2)$ & $12(30.0)$ \\
\hline 5 & $24(18.3)$ & $6(18.2)$ & $8(20.0)$ \\
\hline 6 & $8(6.1)$ & $2(6.0)$ & $4(10.0)$ \\
\hline 7 & $2(1.5)$ & 1 (3.) & $2(5.0)$ \\
\hline 8 & $1(2.5)$ & & \\
\hline Total & 460 (99.9) & $116(99.9)$ & $166(100.0)$ \\
\hline Mean number of Q-HRs & $3.51 \pm 0.168$ & $3.51 \pm 0.254$ & $4.15 \pm 0.244$ \\
\hline
\end{tabular}

\section{Statistics}

$t l, I I=0.080 ; d f=153 ; P=0.936$;

$t l, I I I=2.410 ; d f=160 ; P=0.017$;

$t I I, I I I=1.791 ; d f=71 ; P=0.078$;

As can be seen from [Table-1] there aren't statistically significant differences between Kazakh and Russian samples. However, differences in the mean number of Q-HRs per individual between Kazakhs and Russians from Uyghur sample proved to be statistically significant, viz the mean number of Q-HRs, as the main quantitative characteristic for the content of Q-heterochromatin material in the genome, was considerably higher in the Uyghurs $(3.51,3.51$ and 4.15 , respectively).

The frequencies of Q-HRs in seven Q-polymorphic autosomes and the distribution of their relative frequencies are shown in [Table-2].

[Table-2] demonstrates that three samples do not differ from each other in the relative content ('portion') of chromosomal Q-HRs in seven Q-polymorphic autosomes, if their frequencies to express as percentage of the overall number of chromosomal Q-HR. However, the differences between them are detected when the number of QHRs expressed as a percentage from the number of chromosomes analyzed (176.1\%, $172.5 \%$ and $218.7 \%)$ of Kazakh, Russian and Uighur people, respectively. In other words, the increase in the mean number of Q-HRs are accompanied by increases in absolute Q-HR frequencies on all the autosomes, and vice versa, that matched with all of our previous observations $[4-11,17]$.

Table 2- Q-HR frequencies in seven Q-polymorphic autosomes of Kazakh, Russian and Uyghur samples

\begin{tabular}{|lccc|}
\hline Location of Q-HRs & Kazakhs $(\boldsymbol{n}=131)$ & Russians $(\boldsymbol{n}=33)$ & Uyghurs $(\mathbf{n}=\mathbf{4 0})$ \\
\hline 3 & $109(41.7)^{\star}$ & $37(56.1)$ & $43(53.7)$ \\
& $23.7^{\star *}$ & 31.9 & 25.7 \\
4 & $27(10.3)$ & $6(9.1)$ & $7(8.75)$ \\
13 & 5.9 & 5.2 & 4 \\
& $141(54.0)$ & $33(50.0)$ & $51(63.7)$ \\
14 & 30.6 & 28.4 & 30.8 \\
& $37(14.2)$ & $6(9.1)$ & $13(16.2)$ \\
15 & 8 & 5.2 & 8 \\
& $37(14.2)$ & $11(16.6)$ & $22(27.5)$ \\
21 & 8 & 9.5 & 13.1 \\
& $58(22.2)$ & $11(16.6)$ & $116(20.0)$ \\
22 & 12.6 & 9.5 & 9.7 \\
& $51(19.5)$ & $12(18.1)$ & $14(17.5)$ \\
Total & 11.1 & 10.3 & 8.7 \\
Mean number of Q-HRs & $3.51 \pm 168$ & $3.51 \pm 0.254$ & $4.37 \pm 0.244$ \\
\hline
\end{tabular}

* $Q$-HRs frequency from the number of chromosomes analyzed;

${ }^{* *} Q-H R s$ frequency as percentage of the overall number of chromosomal Q-HR.

In 1982 we examined the Kazakhs aged 13-17 years of Senior Jooze in Kurday area Jambul region of southern Kazakhstan [4] Now, after 30 years we managed to explore Kazakh students in Almaty. Comparative analysis of the distribution of the numbers and the mean number of chromosomal Q-HRs in of these two samples are shown in [Table-3] and [Table-4].

Table 3- Distribution of numbers and mean number of Q-HRs of Kazakh samples in Kurday region of Southern Kazakhstan and

\begin{tabular}{|lcc|}
\multicolumn{3}{c}{$\begin{array}{c}\text { Almaty } \\
\text { Nopulations }\end{array}$} \\
\hline 0 & Kazakhs (Kurday)* $(\mathrm{n}=101)$ & Kazakhs (Almaty) $(\mathrm{n}=131)$ \\
1 & $3(3.0)$ & $14(10.7)$ \\
2 & $6(5.9)$ & $17(13.7)$ \\
3 & $19(18.8)$ & $32(24.4)$ \\
4 & $24(23.8)$ & $33(25.2)$ \\
5 & $20(19.8)$ & $24(18.3)$ \\
6 & $16(15.8)$ & $8(6.1)$ \\
7 & $9(8.9)$ & $2(1.5)$ \\
8 & $2(2.0)$ & \\
Total & $2(2.0)$ & $460(99.9)$ \\
Mean number of Q-HRs & $360(100.0)$ & $3.51 \pm 0.103$ \\
\hline
\end{tabular}

Statistics $t=0.341 ; d f=221 ; P=0.733$

As it is shown in [Table-3] and [Table-4] the two samples of Kazakhs statistically significantly do not differ from each other of all studied by us quantitative characteristics of chromosomal Q-HRs in population.

In 1982 we also studied polymorphisms of chromosomal Q-HRs in 
198 apparently healthy young men and women of Russian nationality [10]. Now, after 30 years we examined the Russian students studying in Almaty. Comparative analysis of these two Russian samples is shown in [Table-5] and [Table-6].

Table 4- Q-HR frequencies in seven Q-polymorphic autosomes of Kazakhs studied in 1982 [10] and 2012 yrs.

\begin{tabular}{|c|c|c|}
\hline Location of Q-HRs & $\begin{array}{c}\text { Populations } \\
\text { Kazakhs (Almaty) }(n=101)\end{array}$ & Kazakhs (Almaty) $(n=131)$ \\
\hline \multirow[b]{2}{*}{3} & $84(41.6)^{*}$ & $109(41.7)$ \\
\hline & $23.3^{* *}$ & 23.7 \\
\hline \multirow{2}{*}{4} & $18(8.9)$ & $27(10.3)$ \\
\hline & 5 & 5.9 \\
\hline \multirow{3}{*}{13} & $103(51.0)$ & $141(54.0)$ \\
\hline & 28.6 & 30.6 \\
\hline & $29(14.3)$ & $37(14.2)$ \\
\hline \multirow{2}{*}{14} & 8.1 & 8 \\
\hline & $33(16.3)$ & $37(14.2)$ \\
\hline \multirow[t]{2}{*}{15} & 9.2 & 8 \\
\hline & $46(22.8)$ & $58(22.2)$ \\
\hline \multirow{2}{*}{21} & 12.8 & 12.6 \\
\hline & $47(23.3)$ & $51(19.5)$ \\
\hline 22 & 13 & 11.1 \\
\hline TTtal & $360(178.2)$ & $460(176.1)$ \\
\hline IT tol & 100 & 99.9 \\
\hline Mean number of Q-HRs & $3.56 \pm 0.168$ & $3.51 \pm 0.103$ \\
\hline
\end{tabular}

${ }^{*} Q-H R$ f frequency from the number of chromosomes analyzed; ${ }^{* *} Q-H R$ s frequency as percentage of the overall number of chromosomal Q-HR.

[Table-5] show that these two Russian samples, unlike the Kazakhs, are statistically significantly different from each other in quantitative content of chromosomal Q-HRs in the genome. These data confirm that the mean number of Q-HRs per individual in the Russian population in the genome, studied in 2012 was significantly higher than that of a Russians, surveyed 30 years ago [10].

Table 5- Distribution of numbers and mean number of chromosomal Q-HRs of Russians studied in 1982* and 2012 yrs.

\begin{tabular}{|lcc|} 
Number of Q-HRs & $\begin{array}{c}\text { Populations } \\
\text { Russians- } 1982^{*}(n=198)\end{array}$ & Russians-2012 $(n=33)$ \\
\hline 0 & $10(5.0)$ & \\
1 & $24(12.1)$ & $2(6.0)$ \\
2 & $47(23.7)$ & $6(18.2)$ \\
3 & $54(27.3)$ & $11(33.3)$ \\
4 & $33(16.7)$ & $5(15.2)$ \\
5 & $25(12.6)$ & $6(18.2)$ \\
6 & $4(2.0)$ & $2(6.0)$ \\
7 & $1(0.5)$ & $1(3.0)$ \\
Total & $568(99.9)$ & $116(100.0)$ \\
Mean number of Q-HRs & $2.87 \pm 0.103$ & $3.51 \pm 0.254$ \\
\hline
\end{tabular}

Statistics $t=2.368 ; d f=229 ; P=0.019$

These two samples of Russians do not differ from each other in the relative content ('portion') of Q-HRs in seven Q-polymorphic autosomes, if they expressed as percentage of the overall number of chromosomal Q-HR [Table-6]. Actually human populations do not differ significantly from each other in the portion of Q-HRs in the Qpolymorphic loci of seven autosomes [16]. However, the differences between these two Russian samples from each other is detected when the number of Q-HRs are expressed as Q-RHs frequency from the number of chromosomes analyzed (143.3\%and $172.5 \%)$. This fact indicates that the increase in the number of Q-HRs in the genome of Russians, studied in 2012, at the same time on all seven autosomes and not by electively mutations those or other Qpolymorphic loci.
Table 6- Q-HR frequencies in seven Q-polymorphic autosomes of Russians, studied in 1982 [10] and 2012 yrs.

\begin{tabular}{|lcc|}
\hline & Populations & \\
Location of Q-HRs & Russians- $1982^{*}(n=198)$ & Russians-2012 $(n=33)$ \\
\hline 3 & $168(42.4)^{*}$ & $37(56.1)$ \\
4 & $29.6^{* *}$ & 31.9 \\
& $9(2.3)$ & $6(9.1)$ \\
13 & 1.6 & 5.2 \\
& $191(48.2)$ & $33(50.0)$ \\
14 & 33.6 & 28.4 \\
& $49(12.4)$ & $6(9.1)$ \\
15 & 8.6 & 5.2 \\
& $62(15.6)$ & $11(16.6)$ \\
21 & 10.9 & 9.5 \\
& $54(13.6)$ & $11(16.6)$ \\
22 & 9.5 & 9.5 \\
& $35(8.8)$ & $12(18.1)$ \\
Total & 6.2 & 10.3 \\
Mean number of Q-HRs & $568(143.3)$ & $116(175.6)$ \\
\cline { 2 - 2 } & 100.0 & 99.9 \\
& $2.87 \pm 0.103$ & $3.51 \pm 0.254$ \\
\hline
\end{tabular}

\section{Discussion}

There is no agreement as to the nature of Q-HRs variability, although arguments are based on the 'selectionist' hypothesis. One approach, implying that Q-heterochromatin with different locations are basically similar in structural and functional features, as defined by us [5] in the following manner: 'of primary importance to an individual is the dose and not the location of $Q$-variants'. The term' dose' is defined as the amount of Q-heterochromatin material in the genome regardless of its location in any chromosome. In other words, this approach is based on the assumption that Q-HRs lack locus-specificity. Those favoring the alternative approach believe that derivations from expected $\mathrm{Q}-\mathrm{HR}$ s frequencies, observed in any loci, reflect some structural and functional features of these loci and are due either to selection or to non fortuitous segregation of chromosomes bearing the given Q-HRs [18-20].

We suppose, that our new data on the populations living in southern Kazakhstan does not contradict hypothesis of a possible selective value of chromosomal Q-HRs in human adaptation to different climatic and geographical conditions of the Earth. Previously, we have repeatedly shown that the amount of Q-chromosomal HRs in the genome of human populations depends largely on the peculiarity of climatic and geographical conditions of their place of residence, and not on their racial and ethnic features $[4-12,16]$. The lack of statistically significant differences in quantitative content of chromosomal Q-HRs between the two Kazakh samples from the southern Kazakhstan should not be surprising. However, the differences between the two Russian samples, permanently residing in the same climatic and geographical conditions, but studied at different times by the amount of chromosomal Q-HRs in the genome really unexpected phenomenon.

In search of the causes of differences in the quantitative content of chromosomal Q-HRs between the Russian samples studied by us, we turned to two well-known demographic processes that took place here in the last two decades:

1. Inter-ethnic marriages, and

2. The mass migration of Russian population from Kazakhstan to Russia after the collapse of the Soviet Union.

So according to "Express K" "In the last 11 years, the number of mixed marriages in Kazakhstan is increased by more than a third". 
According to data from the National Statistical Agency in 1999, such marriages were 18.402, while in 2010-25.669 marriages. More often inter-marriage with members of other nationalities involve Russians and Kazakhs - 8844 and 4246 marriages, respectively " (more details see "Tengrinews.kz"). However, we believe that inter-ethnic marriages could not significantly affect the increase of the number of chromosomal Q-HRs in the genome of Russians living at present in Kazakhstan. First, we included in our sample of young men and women whose parents were of Russian nationality. Secondly, there is no scientific data that themselves inter-ethnic marriages lead to an increase in the number of chromosomal Q-HRs in the genome of the population. Therefore, we are inclined to believe that interethnic marriages could not be the main cause of the observed differences between the two Russian samples at the chromosomal level.

Highly probable that the main reason for such a significant change in the genome in Russians, currently living in southern Kazakhstan, is a mass migration. But this migration has had some features that, in the end, really could have led to a substantial increase in the number of chromosomal Q-HRs in the genome surveyed in 2012 Russian young men and women in Almaty. Such an assumption is evidenced by the following observations. First, the mass migration of Russians in Russia after the collapse of the USSR was peaceful and voluntary, as there were not inter-ethnic conflict, racial, political, economic or other forms of discrimination. For them was a free choice to move to their historical homeland, or stay in Kazakhstan. Second, as it is well known there was no significant economic stratification of population in Soviet Union, so anyone could leave for Russia. Thirdly, the poll of the students indicated that the choice of a permanent residence, their parents were guided mainly by climatic, rather than economic considerations. Indeed, the standard of living of the modern Kazakhstan is one the highest among former Soviet republics. If extremely simplified Russians living in southern Kazakhstan simply preferred a warm climate.

Because the mean number of chromosomal Q-HRs in the populations of the southern Kazakhstan indigenous people has not changed over the last 30 years [Table-3], [Table-4] it is possible that it (mean number) really reflects the optimal amount of Qheterochromatin material in the human genome for life in a that climate and geographical area. If so, then we can assume that generally Russians remained in southern Kazakhstan, in which the amount of chromosomal Q-HRs in the genome were similar to those of the indigenous population. However, this selection was not the result of known in science population genetic processes, and was the result of a free and of conscious choice by individuals places of permanent residence, where the determining factor was the climate. But the impetus for this selection has served not expected Soviet collapse, population genetic consequences of which remains to be explored.

Relatively large number of chromosomal Q-HRs in the genome of our Uyghur sample compared with native inhabitants of southern Kazakhstan also be explained in terms of 'selectionist' hypothesis. It is known that as an ethnic Uyghurs were formed to the south of present-day Kazakhstan, in warm and mild climate of the basin of the river Tarim. In southern Kazakhstan, they have appeared recently and, fortunately, have successfully adapted, as evidenced by a significant increase in their numbers (see above). Furthermore, unlike Kazakhs the Uyghurs were not nomads and traditionally were engaged in agriculture, crafts and trade.
In the present study we were unable to choose unequivocally one of the explanations for the possible selective value of chromosomal QHRs: locus-specific or integral selectivity determined by the overall amount of Q-heterochromatin in an individual. However, we feel that the results of the comparison of quantitative characteristics in these three groups are strong evidence in favor of hypothesis on the integral selective value of human chromosomal $Q$ heterochromatin regions.

\section{Acknowledgments}

We wish to express our gratitude to the students at the Kazakh National Medical University after name S.D. Asfendyarov in Almaty for their cooperation and contribution to our work.

\section{References}

[1] Buckton K.E., O'Riordan M.L., Jacobs P.A., Robinson J.I., Hill R., Evans H.J. (1976) Ann. Hum. Gene., 40, 90-112.

[2] Lubs H.A., Kimberling W.J., Hecht F., Patil S.R., Brown J., Gerald P., Summit R.L. (1977) Nature, 268, 631-632.

[3] Al-Nassar K.E., Palmer C.G., Connealy P.M., Pao-Lo Yu (1981) Hum. Genet., 57, 423-427.

[4] Ibraimov A.I., Mirrakhimov M.M., Nazarenko S.A., Axenrod E.I., Akbanova G.A. (1982) Hum. Genet., 60, 1-7.

[5] Ibraimov A.I., Mirrakhimov M.M., Axenrod E.I., Kurmanova G.U. (1986) Hum. Genet., 73, 151-156.

[6] Ibraimov A.I., Kurmanova G.U., Ginsburg E.K., Aksenovich T.I., Axenrod E.I. (1990) Cytobios., 63, 71-82.

[7] Ibraimov A.I., Axenrod E.I., Kurmanova G.U., Turapov O.A. (1991) Cytobios., 67, 95-100.

[8] Ibraimov A.I., Karagulova G.O., Kim E.I. (1997) Indian J. Hum. Genet., 3(2), 77-81.

[9] Ibraimov A.I., Mirrakhimov M.M. (1982) Hum. Genet., 62, 252257.

[10]lbraimov A.I., Mirrakhimov M.M. (1982) Hum. Genet., 62, 258260.

[11]lbraimov A.I., Mirrakhimov MM. (1982) Hum. Genet., 62, 261265.

[12] Ibraimov A.I., Mirrakhimov M.M. (1985) Progress and Topics in Cytogenetics, Part A., 213-287.

[13]Stanyon R., Studer M., Dragone A., De Benedicts G., Brancati C. (1988) Int. J. Anthropol., 3(1), 14-29.

[14]Kalz L., Kalz-Fuller B., Hedge B. (2005) Int. J. Hum. Genet., 5 (2), 153-163.

[15]Décsey K., Bellovits O., Bujdoso GM. (2006) Int. J. Hum. Genet., 6(3), 177-183.

[16]Hungerford D.A. (1965) Stain Technol., 40, 333-338.

[17]Ibraimov A.I.( 2010) Trends and Scope of Human Biology, 225250.

[18]Geraedts J.P.M., Pearson P.L. (1974) Clin. Genet., 6, 247-257.

[19]Mikelsaar A.V., Kaosaar M.E., Viikmaa T.N. (1975) Human Genetik, 26, 1-23.

[20]Nazarenko S.A. (1987) Cytol. Genet., 21, 183-186.

[21]lbraimov A.I. (1983) Clin. Genet., 24, 240-242. 